\title{
Shewanella putrefaciens em lesão cutânea traumática
}

\author{
Shewanella putrefaciens in traumatic skin lesions \\ Shewanella putrefaciens en lesión cutánea traumática
}

Antonio Rafael da Silva

Centro de Referência em Doenças Infecciosas e Parasitárias, Departamento de Patologia, Universidade Federal do Maranhão, São Luis, Maranhão, Brasil

Wilma Batista de Matos

Centro de Referência em Doenças Infecciosas e Parasitárias, Departamento de Patologia, Universidade Federal do Maranhão, São Luis, Maranhão, Brasil

José Ferreira Lima

Hospital Universitário Presidente Dutra, Universidade Federal do Maranhão, São Luis, Maranhão, Brasil
André Victor Barbosa

Laboratório de Zoonoses Bacterianas, Fundação Oswaldo Cruz, Rio de Janeiro, Rio de Janeiro, Brasil

\section{Ernesto Hofer}

Laboratório de Zoonoses Bacterianas, Fundação Oswaldo Cruz, Rio de Janeiro, Rio de Janeiro, Brasil

Eloísa da Graça do Rosário Gonçalves

Laboratório de Zoonoses Bacterianas, Fundação Oswaldo Cruz, Rio de Janeiro, Rio de Janeiro, Brasil

\section{RESUMO}

Os autores descrevem o caso de um paciente do sexo masculino, pescador, de 44 anos de idade, que apresentou úlceras infecciosas na perna direita após trauma sofrido enquanto pescava. Foi isolada e identificada a espécie Shewanella putrefaciens, em associação com Staphylococcus aureus e Escherichia coli em cultivo da secreção da ferida. A identificação dos isolados foi feita por meio de procedimento microbiológico padrão e sistema comercial (NF e Vitek GNI). O teste de sensibilidade mostrou sensibilidade da bactéria à maioria dos antibióticos testados.

Palavras-chave: Dermatoses da Perna; Infecções Bacterianas; Úlcera Cutânea; Shewanella putrefaciens.

\section{INTRODUÇÃO}

Shewanella putrefaciens é um bastonete Gramnegativo que tem a capacidade de produzir $\mathrm{H}_{2} \mathrm{~S}$ nos meios de triagem bioquímica'. Primeiramente classificada como Achromobacter putrefaciens, a bactéria iá pertenceu aos gêneros Pseudomonas e Alteromonas ${ }^{2}$. Em 1985, foi classificada no gênero Shewanella ${ }^{3}$, no qual já são reconhecidas 40 espécies com base na caracterização molecular ${ }^{4}$. $\bigcirc$ gênero é originário de ambientes aquáticos ${ }^{4,5}$, tendo o primeiro isolamento da espécie Shewanella putrefaciens a partir de material humano sido descrito em $1963^{6,7}$. A participação desta bactéria em processos patológicos humanos é considerada rara.

\footnotetext{
Correspondência / Correspondence / Correspondencia:

Eloísa da Graça do Rosário Gonçalves

Centro de Referência em Doenças Infecciosas e Parasitárias, Departamento de Patologia, Universidade Federal do Maranhão

Praça Madre Deus, 02, Térreo. Bairro: Madre Deus

CEP: 65025-560 São Luís-Maranhão-Brasil

Tel.: (98) 3221-0270

E-mail: regionalsbmt@elo.com.br
}

No entanto, o espectro clínico atribuído à infecção por este agente é muito variado, compreendendo o comprometimento localizado de pele e tecido celular subcutâneo à bacteremia, com manifestações graves e desfecho fulminante ${ }^{8,6,9,7,5}$. Os autores descrevem um caso de infecção de pele e tecido celular subcutâneo, de longa duração e com evolução para úlceras, de cujo material foi isolada flora bacteriana mista contendo a espécie Shewanella putrefaciens, incomum em processos semelhantes.

\section{DESCRIÇÃO DO CASO}

Paciente do sexo masculino, de 44 anos de idade, pescador, natural e residente no Município de Arari, situado às margens do rio Mearim, na região centro-oeste do Estado do Maranhão. Em abril de 2005, sofreu traumatismo na altura do joelho e terço superior da perna direita, ao escorregar e cair no fundo de uma canoa, quando pescava. No local traumatizado iniciou-se processo inflamatório, com edema e vermelhidão, que evoluiu com o surgimento de fístulas. O quadro progrediu nos meses seguintes, com ampliação da área inflamada, surgimento de novas fístulas e eliminação de secreção 
purulenta. Procurou, então, auxílio médico em seu município, tendo feito uso empírico e sucessivo de Clindamicina, Penicilina Benzatina e Cefalexina por tempo prolongado, obtendo apenas discreta melhora na intensidade dos sintomas. Em janeiro de 2006, foi encaminhado ao Centro de Referência em Doenças Infecciosas e Parasitárias da Universidade Federal do Maranhão (UFMA), onde se apresentou, exibindo lesões ulceradas, de bordas irregulares, de diâmetros variados, com secreção piossanguinolenta, grande área de edema e hiperemia (Figura 1). Referiu que dez dias antes comparecera a serviço de emergência, onde fora submetido a desbridamento cirúrgico das lesões e estudo radiológico do joelho, o qual não mostrara alterações ósseas. $\mathrm{Na}$ investigação de antecedentes mórbidos pessoais negou outras doenças, alcoolismo e tabagismo. Amostras da secreção da ferida foram colhidas para cultivo, tendo sido empregado para transporte o meio de Cary and Blair e para o isolamento, os meios de ágarsangue e ágar MacConkey. Houve crescimento e isolamento das espécies: Staphylococcus aureus, Escherichia coli e Shewanella putrefaciens. A identificação bioquímica desta última foi feita com o emprego do Kit NF Il (Probac do Brasil) e pelo sistema automatizado VITEK Gram negative identification (GNI). Pelo método convencional complementar, a caracterização da espécie se baseou no seguinte perfil fenotípico: ação oxidativa sobre a glicose, em meio O-F; crescimento em ágar MacConkey, incubado nas temperaturas de 25 e $35^{\circ} \mathrm{C}$; ausência de crescimento em ágar SS; crescimento em água peptonada sem $\mathrm{NaCl}$; ausência de crescimento em meio contendo $6 \mathrm{~g} \%$ de $\mathrm{NaCl}$ e produção de ornitinadescarboxilase.

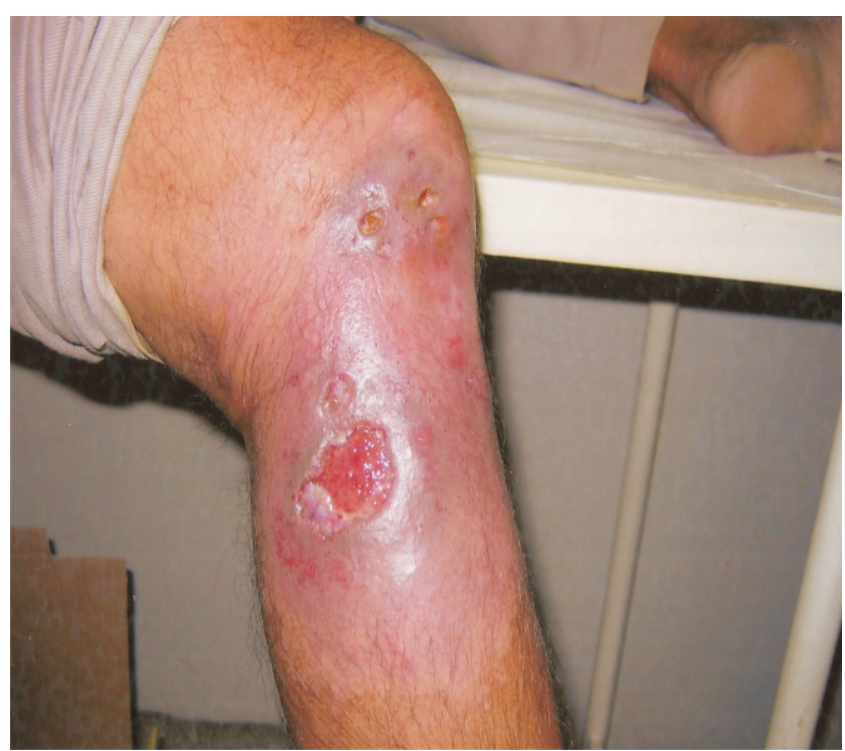

Figura 1 - Lesões ulceradas traumáticas, rodeadas por edema e hiperemia. São Luís, Maranhão, Brasil, 2006

Testes de sensibilidade a antimicrobianos foram feitos pelo método de Kirby-Baver, com o emprego do meio de Müller-Hinton e discos de antibióticos para as séries Gramnegativa e Gram-positiva (CECON), obtendo-se os perfis de sensibilidade mostrados no quadro 1.

\begin{tabular}{|c|c|c|c|}
\hline Antibióticos testados & S. putrefacies & S. aureus & E. coli \\
\hline Penicilina & NT & $R$ & NT \\
\hline Oxacilina & NT & $R$ & NT \\
\hline Ampicilina & $S$ & $\mathrm{R}$ & S \\
\hline Ampicilina - sulbactam & NT & $R$ & NT \\
\hline Clindamicina & NT & $\mathrm{R}$ & NT \\
\hline Cefalotina & NT & $R$ & NT \\
\hline Cefazolina & NT & $\mathrm{R}$ & NT \\
\hline Cefepime & S & NT & NT \\
\hline Cefotaxima & S & NT & $S$ \\
\hline Cefoxitina & S & NT & NT \\
\hline Ceftazidina & S & NT & $S$ \\
\hline Ceftriaxona & NT & NT & S \\
\hline Eritromicina & NT & $R$ & NT \\
\hline Tetraciclina & $R$ & NT & $\mathrm{R}$ \\
\hline Cloranfenicol & NT & $\mathrm{R}$ & NT \\
\hline Cotrimoxazol & $\mathrm{R}$ & $R$ & $R$ \\
\hline Gentamicina & NT & $\mathrm{R}$ & S \\
\hline Amicacina & $S$ & $\mathrm{R}$ & S \\
\hline Tobramicina & S & NT & S \\
\hline Ciprofloxacin & S & $\mathrm{R}$ & $S$ \\
\hline Norfloxacin & S & NT & NT \\
\hline Polimixina B & S & NT & S \\
\hline Ácido nalidíxico & S & NT & NT \\
\hline Ticarcilina - clavulanato & S & NT & NT \\
\hline Meropenem & S & NT & S \\
\hline Aztreonam & $\mathrm{R}$ & NT & $\mathrm{R}$ \\
\hline Teicoplanina & NT & S & NT \\
\hline Vancomicina & NT & $S$ & NT \\
\hline
\end{tabular}

S: sensível; R: resistente; NT: não testado.

Quadro 1 - Sensibilidade a antimicrobianos de bactérias isoladas em lesão cutânea traumática. São Luis, Maranhão, Brasil, 2006

Foi instituído tratamento com Ciprofloxacin, na dose de $500 \mathrm{mg}$ a cada $12 \mathrm{~h}$, constatando-se melhora moderada do quadro infeccioso. Após duas semanas de tratamento, foi associada Amicacina, mantendo-se o tratamento pelo tempo total de 55 dias. $O$ paciente foi seguido, tendo sido revisto aos dois, quatro e seis meses após o término do tratamento, recebendo alta com as lesões totalmente cicatrizadas.

\section{DISCUSSÃO}

A demonstração precisa dos mecanismos de produção de feridas na pele e tecido celular subcutâneo, assim como da colonização e introdução de bactérias, é importante na definição dos procedimentos laboratoriais destinados ao esclarecimento da etiologia da infecção bacteriana e para a terapêutica específica. No caso descrito, considerandose a atividade habitual exercida pelo paciente, assim como a história de traumatismo produzido no exercício 
profissional, a veiculação da espécie Shewanella putrefaciens pode ter-se dado, mais provavelmente, a partir do contato da área traumatizada com a água do rio, bem como do manuseio de peixes e de outras fontes oriundas do ambiente aquático, à semelhança de infecções produzidas por membros da família Vibrionaceae em circunstâncias similares ${ }^{10}$. Ressalta-se que, em todo o processo de investigação diagnóstica, não foram constatadas outras condições mórbidas associadas que pudessem favorecer o processo infeccioso. $\bigcirc$ isolamento de flora bacteriana mista contendo a Shewanella putrefaciens em espécimes clínicos obtidos em infecções de pele e tecido celular subcutâneo e em pacientes septicêmicos é referido por outros autores ${ }^{6,7}$. Em um estudo de 16 pacientes com quadro de bacteremia, a Shewanella putrefaciens foi isolada em cultura pura em apenas dois ${ }^{7}$. Estas observações tornaram difícil definir o papel preciso desta espécie, considerada um patógeno secundário ou oportunista ${ }^{4}$. Contudo, no caso descrito, a resposta clínica insatisfatória aos agentes antimicrobianos com espectro de ação sobre Gram-positivos, usados empiricamente pelo paciente, sugere um papel secundário da espécie Staphylococcus aureus na produção do quadro clínico. Por outro lado, o perfil semelhante de sensibilidade aos antimicrobianos da Shewanella putrefaciens e da Escherichia coli mostra a ação dos Gram-negativos no processo, sendo o papel patogênico efetivo da Shewanella putrefaciens reforçado pelo mecanismo de produção da ferida e contato com o ambiente aquático.

\section{CONCLUSÃO}

caso descrito mostra a possibilidade de infecção de feridas da pele e do tecido celular subcutâneo pela Shewanella putrefaciens, no contato humano com ambientes aquáticos. Este fato, aliado à sensibilidade in vitro da bactéria à maioria dos antibióticos testados, justifica a investigação etiológica em circunstâncias clínico-epidemiológicas semelhantes, o que permitirá o tratamento específico dos casos, tendo em vista o potencial patogênico da bactéria.

\section{Shewanella putrefaciens in traumatic skin lesions}

\section{ABSTRACT}

The authors describe the case of a 44 -year old fisherman who presented with infectious ulcers on his right leg after suffering a trauma while fishing. The species Shewanella putrefaciens, Staphylococcus aureus and Escherichia coli were isolated and identified from a culture of the wound secretion. The isolates were identified by standard microbiological procedures and commercial identification systems (NF and Vitek GNI). Shewanella putrefaciens was sensitive to the majority of antibiotics tested.

Keywords: Leg Dermatoses; Bacterial Infections; Skin Ulcer; Shewanella putrefaciens.

\section{Shewanella putrefaciens en lesión cutánea traumática}

\section{RESUMEN}

Los autores describen el caso de un paciente de sexo masculino, pescador, de 44 años de edad, que presentó úlceras infecciosas en la pierna derecha luego de un traumatismo sufrido mientras pescaba. Fue aislada e identificada la especie Shewanella putrefaciens, asociada a Staphylococcus aureus y Escherichia coli en cultivo de secreciones de la herida. La identificación de los aislados se hizo por medio de procedimiento microbiológico estándar y sistema comercial (NF y Vitek GNI). El test de sensibilidad mostró sensibilidad de la bacteria a la mayoría de los antibióticos probados.

Palabras clave: Dermatosis de la Pierna; Infecciones Bacterianas; Úlcera Cutánea; Shewanella putrefaciens.

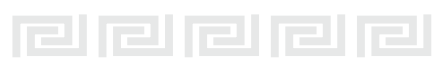

\section{REFERÊNCIAS}

1 Khashe S, Janda JM. Biochemical and pathogenic properties of Shewanella alga and Shewanella putrefaciens. J Clin Microbiol. 1998;36:783-7.

2 Baumann L, Baumann P, Mandel M, Allen RD. Taxonomy of aerobic marine eubacteria. J Bacteriol. 1972 Apr; 1 10(1):402-29.
3 MacDonell MT, Colwell RR. Phylogeny of the Vibrionaceae, and recommendation for two new genera, Listonella and Shewanella. Syst Appl Microbiol. 1985;6:171-82.

$4 \mathrm{Hau} H \mathrm{H}$, Gralnik JA. Ecology and biotechnology of the genus Shewanella. Annu Rev Microbiol. 2007; $61: 237-58$. 
5 Levy PY, Tessier JL. Arthritis due to Shewanella putrefaciens. Clin Infect Dis. 1998 Feb;26(2):536.

6 Brink AJ, van Straten A, van Rensburg AJ. Shewanella (Pseudomonas) putrefaciens bacteremia. Clin Infect Dis. 1995 May;20(5):1327-32.

7 Chen YS, Liu YC, Yen MY, Wang JH, Wang JH, Wann $S R$, et al. Skin and soft-tissue manifestations of Shewanella putrefaciens infections. Clin Infect Dis. 1997 Aug;25(2):225-9.

8 Appelbaum PC, Bowen AJ. Opportunistic infection of chronic skin ulcers with Pseudomonas putrefaciens. $\mathrm{Br}$ J Dermatol. 1978 Feb;98(2):229-31.
9 Butt AA, Figueroa J, Martin DH. Ocular infections caused by three unusual marine organisms. Clin Infect Dis. 1997 Apr;24(4):740.

10 Rodrigues SMA, Gonçalves EGR, Mello DM, Oliveira EG, Hofer E. Pesquisa de bactérias do gênero Vibrio em feridas cutâneas de pescadores do município de Raposa - MA. Rev Soc Bras Med Trop. 2001 ;34:40711.

Recebido em / Received / Recibido en: 22/5/2010 Aceito em / Accepted / Aceito en: 27/8/2010 